\title{
Measuring Regenerative Braking Electricity Generated by the City Bus with Internal Combustion Engine
}

\author{
Mirosław Wendeker', Michał Gęca' ${ }^{1}$ Łukasz Grabowski ${ }^{1 *}$, Grzegorz Barański' \\ 1 Faculty of Mechanical Engineering, Lublin University of Technology, Nadbystrzycka 36, Lublin, Poland \\ * Corresponding author's e-mail: I.grabowski@pollub.pl
}

\begin{abstract}
Engine braking, just when the vehicle consumes no fuel, is an important component of the energy balance. In such states, the bus loses its cumulated kinetic and potential energies but alternators recover a portion of these energies into electricity. Simultaneously, electricity consumption in the diesel-engine city bus is a key component of the overall energy balance. A total energy output of receivers can be more than $4 \mathrm{~kW}$. This paper presents the research results on performance of a serial bus driving varied urban routes. The recorded and investigated parameters include a total amount fuel and electricity consumed and an amount of electricity generated. Engine braking states were calculated with a created algorithm. On average, $17 \%$ of electricity was generated by bus engine braking. The research results and investigation refer to the entire year.
\end{abstract}

Keywords: energy recovery, city bus, electricity consumption.

\section{INTRODUCTION}

The vehicle in motion has kinetic energy, when it drives down, it has potential energy and energy of rotating masses. When the vehicle brakes or drives down, energy recuperation (recovery) is possible regardless of the time of day or year. This energy can be used immediately or stored in several buffers during vehicle's operation.

In a typical solely internal combustion engine bus, energy is stored by the use of air in a passenger section, rechargeable batteries or compressed air in vehicle's pressure vessels [1]. The $10{ }^{\circ} \mathrm{C}$ difference in temperature in a bus passenger section corresponds to the $0.7 \mathrm{MJ}$ difference in energy for a volume of $70 \mathrm{~m}^{3}$. A $24 \mathrm{~V}$ battery stores $19 \mathrm{MJ}$ of energy. The volume of the air vessel in a typical bus is about $120 \mathrm{dm}^{3}$ and the pressure is $10 \mathrm{bar}$. The energy consumed by the compressor to increase the pressure up to 10 bar is $0.8 \mathrm{MJ}$. All the energy stored in these buffers cannot be used but $10-20 \%$ of the total energy of these systems can be saved [2].

Regenerative braking systems are frequently applied in hybrid and electric passenger car drive systems $[3,4]$. They have been commercialized by car and car spare parts manufacturers like Toyota, Honda and Continental [5]. A key source of additional energy in hybrid and electric vehicles is energy recovered from braking. A correctly controlled electric engine operates then as a generator that converts kinetic energy into electricity [4]. An energy recovery system significantly affects the balance of energy consumption during vehicle's operation. A share of recovered braking energy during various driving cycles (ECE in Europe, UDDC in the USA and 10-15 in Japan) can reach $60.1 \%, 43.3 \%$ and $52.5 \%$, respectively [6].

But regenerative braking systems mounted in city buses with only diesel combustion engines have been rarely seen. During a single braking event, the available gross energy input depends on vehicle's initial speed and weight to be significant for the city bus. While net energy input (to be used) is much smaller due to the efficiency of mechanical-into-electrical energy conversion. At a given value of regulated voltage, there is a given rotational speed at alternator terminals where load is constant depending on current. This 
property combined with the possibility to reach a speed of 2,000 rpm can be used in energy braking recuperation. The constant value of energy input in a wide range of speed change is transmitted into on-board receivers.

In the overall energy balance of today's internal-combustion engine buses, electricity consumption continues to grow because of the increasing number of electrical receivers and many new functions of the vehicle to be introduced. According to the study by the European Automobile Manufacturers Association ACEA (March 2011, Brussels) [7], the city bus consumes about $26 \%$ of fuel to power additional propulsion systems $(7 \%$ for a cooling fan, $6 \%$ for alternators, $6.5 \%$ for an air compressor, $2.4 \%$ for a steering pump, $4 \%$ for an air conditioning compressor). Electrical systems such as monitors, punchers, backlights make a travel more comfortable but also significantly load, i.e. about $1.9 \mathrm{~kW}$ the bus electrical installation [8]. An automatic air conditioning (AC) system is an important energy receiver as passengers expect a comfortable travel and public transport is promoted as an alternative method to private car transport. The amount of power consumed by an air conditioner covers the amount of mechanical power transmitted from the engine shaft to the compressor drive and the amount of electric power to drive cooling fans that cool the heat exchanger and ventilation fans. The AC system at its maximum power in a large bus consumes even 25-30 kW to power the compressor and fans [8].

The generation of electricity from chemical energy by transmitting mechanical energy to the alternator via a belt drive during fuel combustion in the diesel engine has low efficiency which is in total about $14 \%$ [9]. This efficiency is even lower at low engine speeds (at idling and slow driving). However, certain engine performance research shows that the share of idle speed by the city bus in city traffic can reach even $43 \%$ [10]. On-board electricity generation means an increased fuel consumption, and as the performance research indicates this is about $25 \%$ of the total city bus fuel consumption. Urban transport currently produces $40 \%$ of $\mathrm{CO}_{2}$ emissions in road traffic in Europe [11] Actually, fleets of large buses for public transport have a significant portion are diesel vehicles whose emissions accumulated in small urban spaces much contributes to civilization diseases.

A continuously increasing demand for electric power results in making on-board power alternators be as powerful as possible. On board, there are mounted 3 to 4 alternators so that each vehicle had a positive electric energy balance of a minimum of $200 \mathrm{~W}$. Accordingly, electrical systems and their components are developed to show both high power and high voltage [12]. The growing demand for electricity and the need to reduce toxic emissions also results in developing ecological systems to generate extra electricity, e.g. flexible photovoltaic modules mounted on the roof, which supports the operation of alternators and charge batteries in conventional combustion-engine vehicles $[8,7,10]$. The only constraints are the amount of solar energy that could be absorbed at daytime and in some seasons of the year only and a limited area of vehicle's roof.

Fuel economy and toxic emissions of conventional vehicles depend on vehicle parameters (mass, rolling resistance, aerodynamic drag), a test cycle and driver's behavior. Test results are affected by both experimental uncertainties and tolerances in vehicle parameters such as the mass and coast down coefficients. An uncertainty up to $\pm 10 \%$ can be expected for fuel consumption and emissions, making statistical distributions more reliable than a single value from a test [13]. Therefore, our research results refer to the entire year of operation of a single vehicle.

The amount of braking electricity generated by the city bus was measured and examined here and then its share was defined and related to the total amount of on-board generated electricity. The electric installation was fitted with neither any system to load alternators nor any additional electricity-storage buffer system.

\section{RESEARCH OBJECT AND METHODOLOGY}

The research object was a city bus Mercedes Conecto 12LF (Fig. 1). This is a 12-meter lowfloor bus for a total of 94 passengers, i.e. 26 seats and 68 standing passengers. The bus is fitted with the OM926 engine and a four-speed automatic gearbox Voith 854.3. The vehicle has a set of three alternators to generate a maximum current of $340 \mathrm{~A}$. Two $100 \mathrm{~A}$ alternators are connected to the crankshaft by means of a 4:1 transmission belt. The alternators operate electrically in parallel. An alternator of a $140 \mathrm{~A}$ is also driven with a 2.71:1 transmission belt. This device is connected to the electrical installation by an extra cable.

The research bus was equipped with a real-time data acquisition system with a data acquisition card module Compact Rio ncRIO 9024 by National 


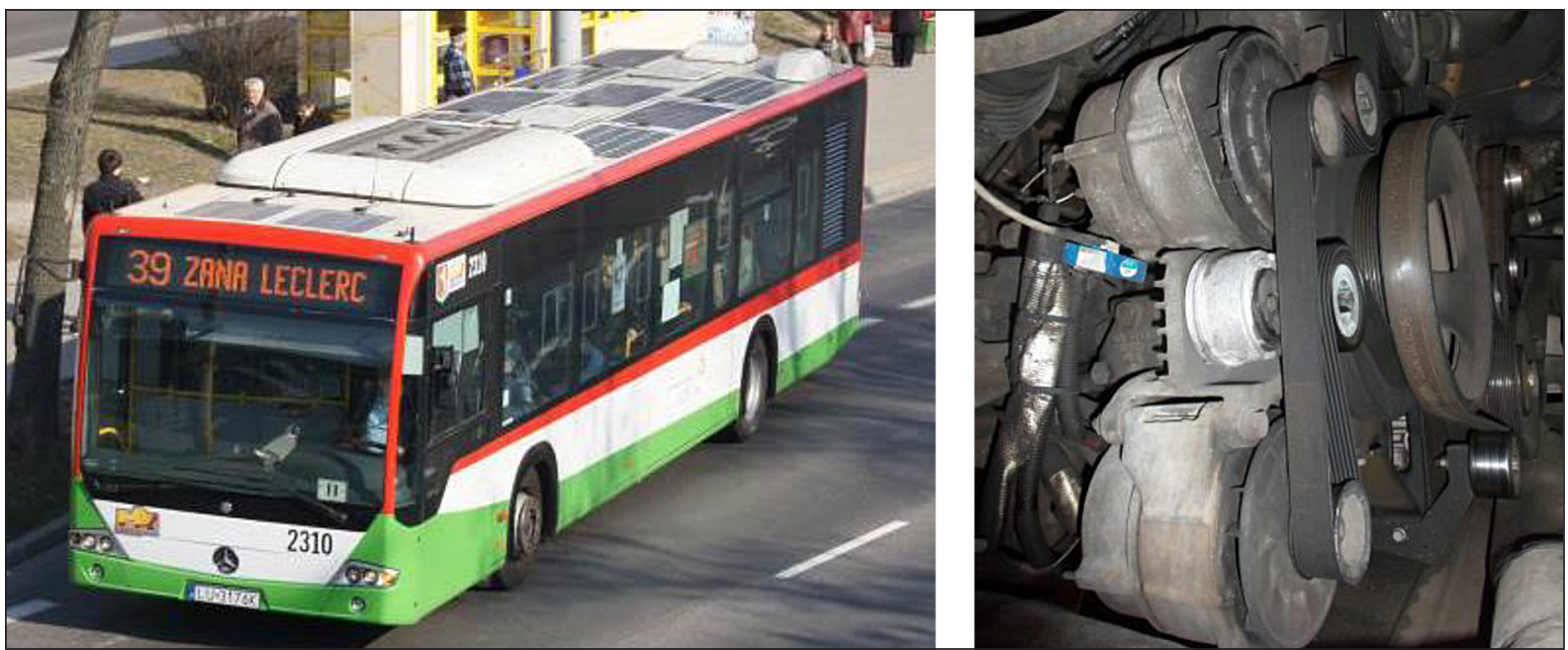

Fig. 1. Mercedes Conecto 12LF and the tested engine with alternators

Instruments to measure certain parameters. Also, a special software in the LabView environment was created to monitor and register voltage $(U)$ and current $(I)$ in the electrical installation. Current was measured with current transducers HTR 300SB mounted on the cable connecting the alternator and the battery. These measurements enabled us to calculate the amount of electricity generated and consumed on board. In addition, the diagnostic transmission from the bus provided us with the following information: engine crankshaft rotational speed $(n)$, fuel consumption per hour $\left(G_{h}\right)$, vehicle speed $(V)$ and acceleration pedal position $(A P P)$. The communication protocol of the Profibus network is defined by the DIN 19245 standard that describes the physical, linear and application aspect of the seven-layer ISO/OSI model. Specific information was read with a special software, i.e. an interface capable of converting the data provided by the standard FMS transmission into data recordable as a file according to a model of the TDMS data (Binary LabVIEW Measurement File). Accordingly, the storage space to save measurements was successfully reduced so the results were examined in the NI Diadem. Figure 2 shows a schematic of the measuring system mounted on the bus. Also, the following parameters were recorded:

- route $(R)$,

- $\operatorname{load}(L)$,

- operating time $\left(t_{e}\right)$,

- engine temperature $\left(T_{e}\right)$,

- ambient temperature $\left(T_{o}\right)$.

This vehicle belongs to the fleet of Miejskie Przedsiębiorstw Komunikacyjne [Municipal Transport Company] in Lublin that owns 22 such buses. In total, 218 buses and 110 trolley buses are used for public transport in Lublin (Eastern Poland) with a population of 300000 people.

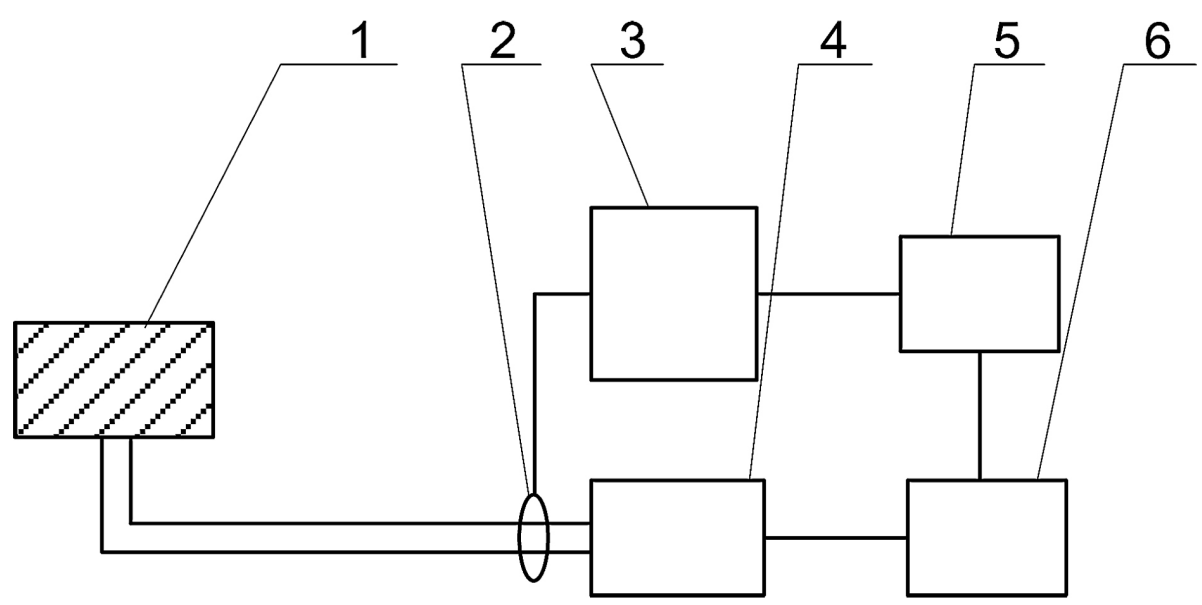

Fig. 2. Measurement system diagram: 1 - battery, 2 -current transducer, 3 - Compact Rio ncRIO 9024 , 4 - alternators, 5 - engine, 6 - FMS controller 
The research was conducted in standard operating conditions to identify real operating conditions for alternators. All of the parameters were recorded on a daily basis between 4:00 and 23:30 (daily bus operation). The results were recorded with a frequency of $2 \mathrm{~Hz}$. The research results to be examined refer to the entire year so that the impact of varied weather and load conditions on vehicle's operation could be specified. To verify bus routes, the Garmin GPS receiver was mounted on the bus. A sample route on a given day is shown in Figure 3. The bus operated over the year on different routes.

Figures 4 and 5 depict sample one-day measurements. The characteristic repeating breaks are the stops at bus stops. These are: voltage $(U)$ and

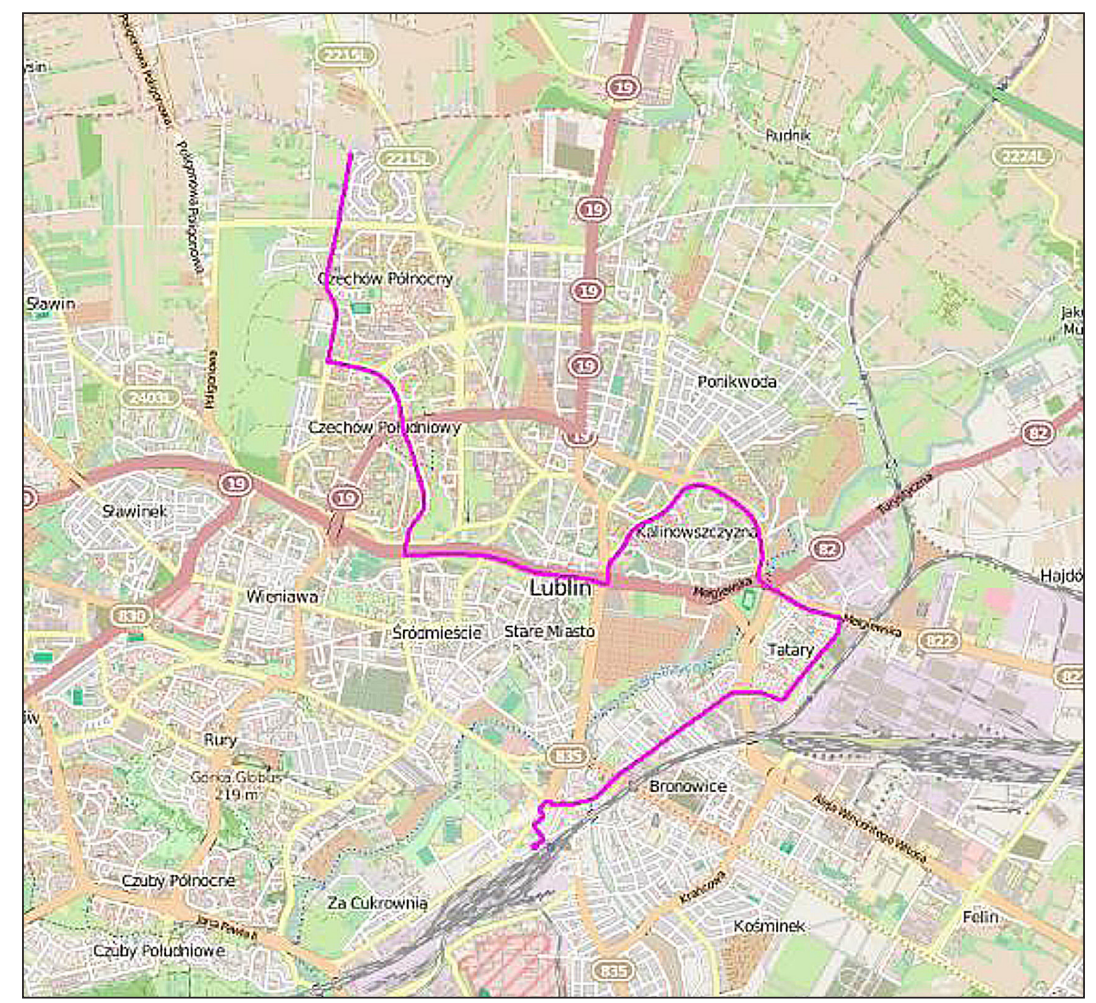

Fig. 3. Mercedes Conecto bus sample route in Lublin

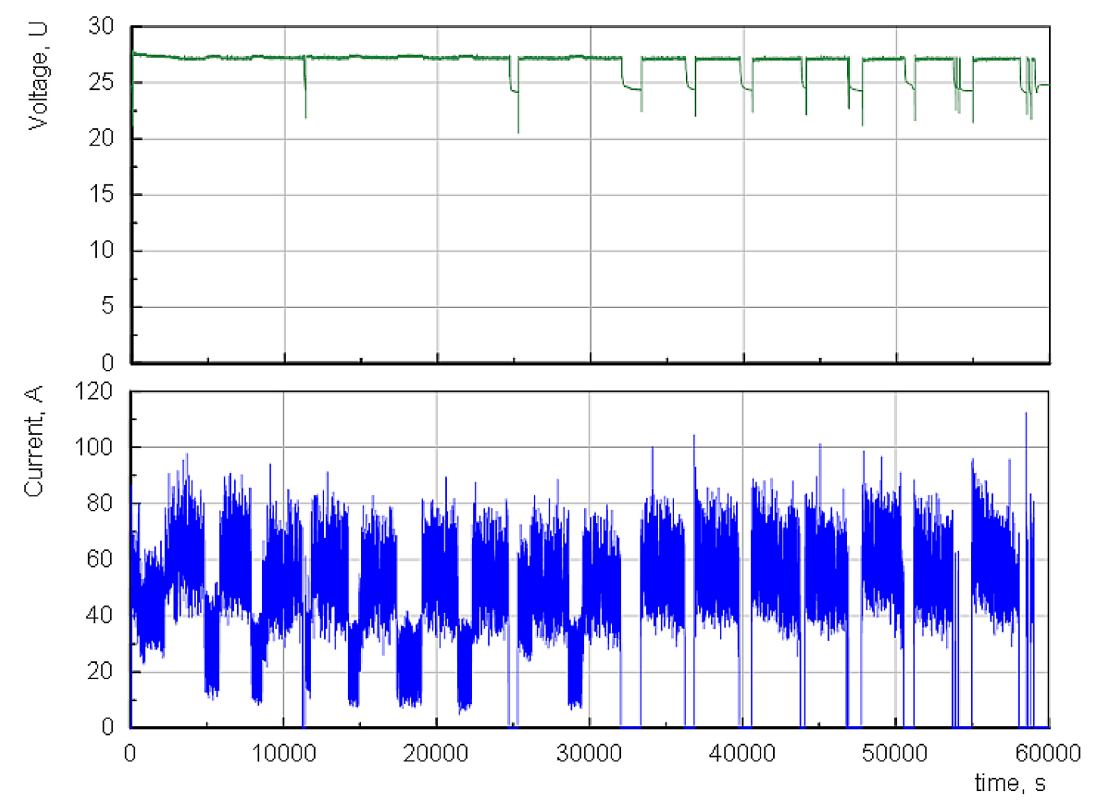

Fig. 4. Voltage and current in the bus electrical installation 
a)

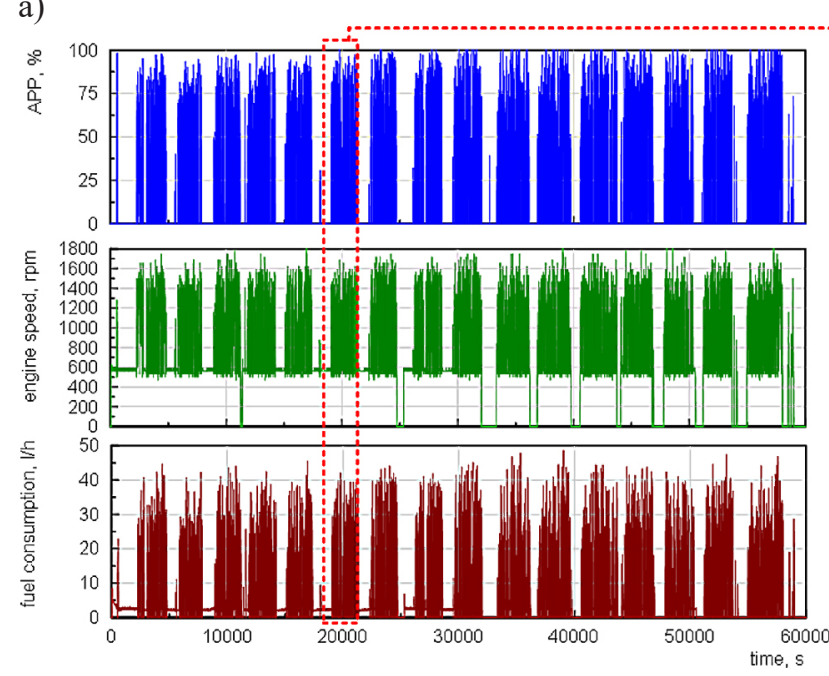

b)

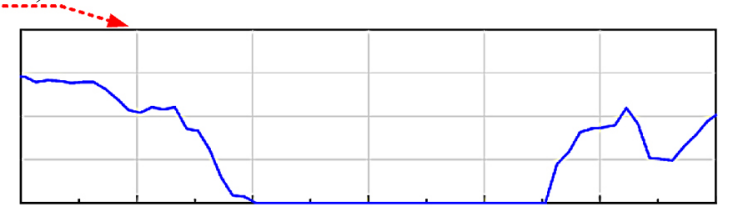

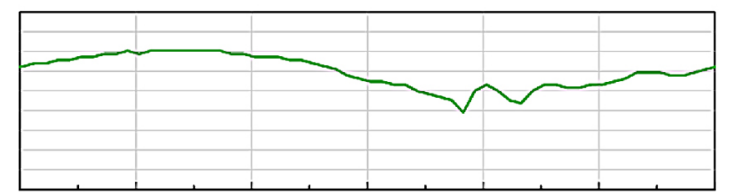

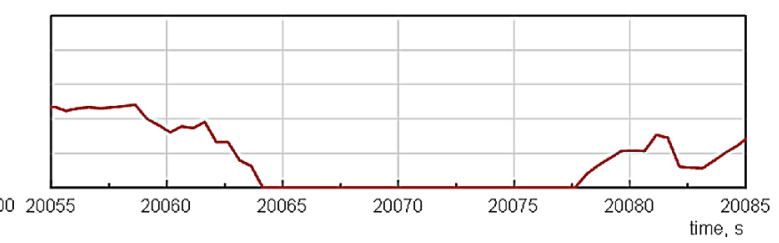

Fig. 5. Changes in the operating parameters: a) daytime operation, b) engine braking

current $(I)$ in the electrical installation of the bus, accelerator pedal position (APP), crankshaft rotational speed $(n)$, fuel consumption per hour $\left(G_{h}\right)$. During a single driving event between stops, the average voltage is $28 \mathrm{~V}$. When alternators produce no electricity at a stop, the battery voltage is $24 \mathrm{~V}$ though it drops even to $22 \mathrm{~V}$ during a start-up. Figure $5 \mathrm{~b}$ depicts the selected parameters during engine braking. This operating state confirms that $A P P$ and $G_{h}$ are 0 and crankshaft speed decreases.

The research results enabled us to specify the amount of recuperated engine braking electricity. The results were compared with a total demand for electricity. Also, there was recorded a total operating time of the internal combustion engine so the operating time of the electricity generation system. There was created the algorithm to calculate engine braking. All calculations were made with the use of the NI Diadem, and a calculation script was created in the Visual Basic programming language to automatically calculate, referring to all files, the data on the entire year. The investigated parameters included the generated electricity, operating time and operating fuel consumption. The investigation of the research results enabled us to specify an operating state with engine braking, which is based on the defined conditions to be satisfied simultaneously to be regarded so, and these conditions include:

$$
\text { Engine braking }\left\{\begin{array}{c}
G_{h}=0 \\
n>0 \\
A P P=0 \\
v=0
\end{array}\right.
$$

where: $G_{h}$ - fuel consumption $\left[\mathrm{dm}^{3} / \mathrm{h}\right], n-$ crankshaft speed [rpm], APP - accelerator pedal position [\%], $v-$ vehicle speed $[\mathrm{km} / \mathrm{h}]$.
During the engine braking state, the accelerator pedal position is $0 \%$, an engine consumes no fuel but vehicle's and engine's speeds are more than 0 . The automatic gearbox reduces gear until neutral gear where the engine is at idle and fuel consumption is more than 0 .

The amount of electricity generated was calculated for each of the operating states. Instantaneous electrical power is defined as the product of current and voltage in the bus electrical installation.

$$
P_{e}(t)=U(t) \cdot I(t)
$$

where: $P$ - electrical power [W], $U$ - voltage [V], $I-$ current $[\mathrm{A}], t-$ time $[\mathrm{s}]$.

Energy generated by alternators over a given period of time, i.e. between 4:00 and 23:30, was calculated as an integral marked by instantaneous power where the limits of integration are as follows: $t_{1}=0$ and $t_{2}=70200 \mathrm{~s}$, which corresponds 19 hours and 30 minutes per day.

$$
E_{e}=\int_{t_{1}}^{t_{2}} P_{e}(t) d t
$$

where: $E$ - electrical energy [kWh], $P$ - electrical power $[\mathrm{W}], t$ - time $[\mathrm{s}]$.

The next stage of the research was to specify the operating times of each operating states, calculated form the results of daytime measurements. For each recorded sample from the sampling time $\Delta t=0.5 \mathrm{~s}$ in a given operating state, the signal of crankshaft speed was quantized. Two signal levels were adopted. The sample quantization function $Q$ is given by Formula 5. A value of 0.5 is assigned to samples for operation over 
a given period of time, whereas a value of 0 was assigned to the remaining measurements.

$$
Q(i)=\left\{\begin{array}{c}
0.5 \text { when } i \in i_{\text {braking }} \\
1 \text { when } i \notin i_{\text {braking }}
\end{array}\right.
$$

Then the values were added and time was calculated and given in hours:

$$
\mathrm{t}_{e}=\sum_{i=1}^{k} Q(i)
$$

where: $Q(i)$ - quantization [-], $i$ - sampling, $i_{\text {braking }}-$ engine braking sampling, $t_{e}-$ time $[\mathrm{h}]$.

The registered fuel consumption per hour was applied to calculate a total fuel consumption. Over a period of time, i.e. between 4:00 and 23:30, it was calculated as an integral marked from fuel consumption per hour where the limits of integration are as follows: $t_{1}=0$ and $t_{2}=70200 \mathrm{~s}$, as for electrical energy.

$$
\mathrm{G}=\frac{1}{7200} \int_{t_{1}}^{t_{2}} G_{h}(t) d t
$$

where: $G$ - total fuel consumption $\left[\mathrm{dm}^{3}\right], G_{h}-$ fuel consumption per hour $\left[\mathrm{dm}^{3} / \mathrm{h}\right], t-$ time $[\mathrm{s}]$.

\section{EXAMINING THE RESEARCH RESULTS}

Figure 6 shows the amount of electrical energy generated on-board over varied operating periods. The results are correlated to the total operating time, i.e. the period when electricity is generated in a set of alternators. The amount of electricity consumed is proportional to the operating time given in hours. The conclusion is that the highest demand for electricity was in March, i.e. $461 \mathrm{kWh}$, whereas in August it was $291 \mathrm{kWh}$ only. This difference is due to a shorter operating time in summer months. The higher power consumption is at low or high temperatures and results from the use of heating or

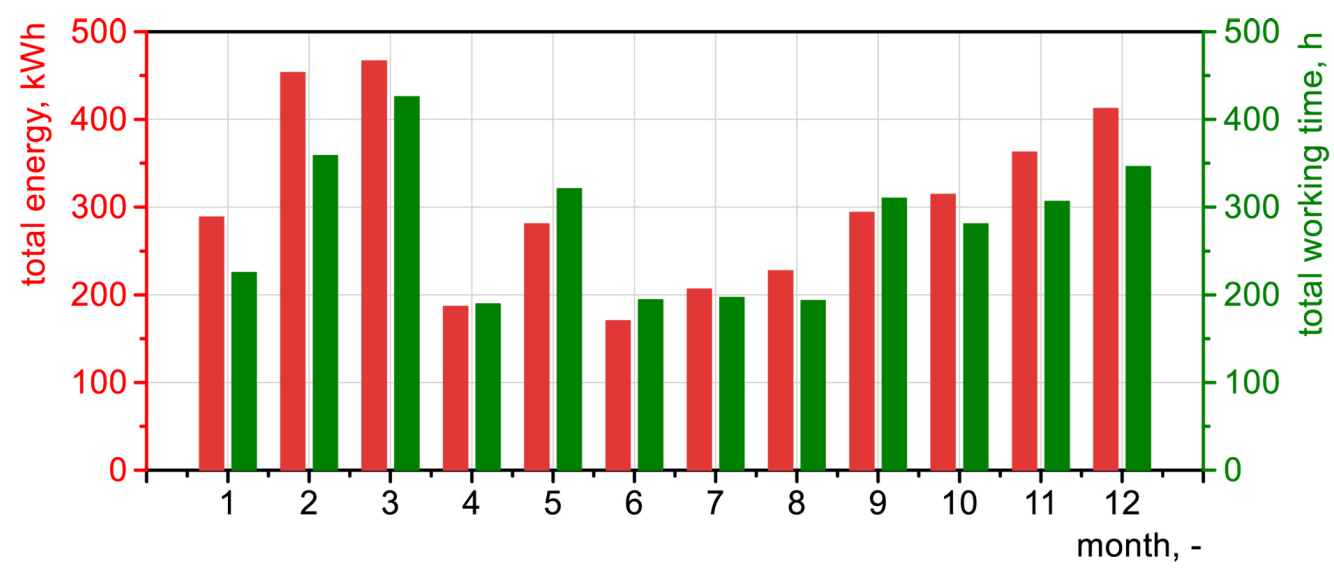

Fig. 6. Total amount of electricity generated and consumed on board and the total operating time over months

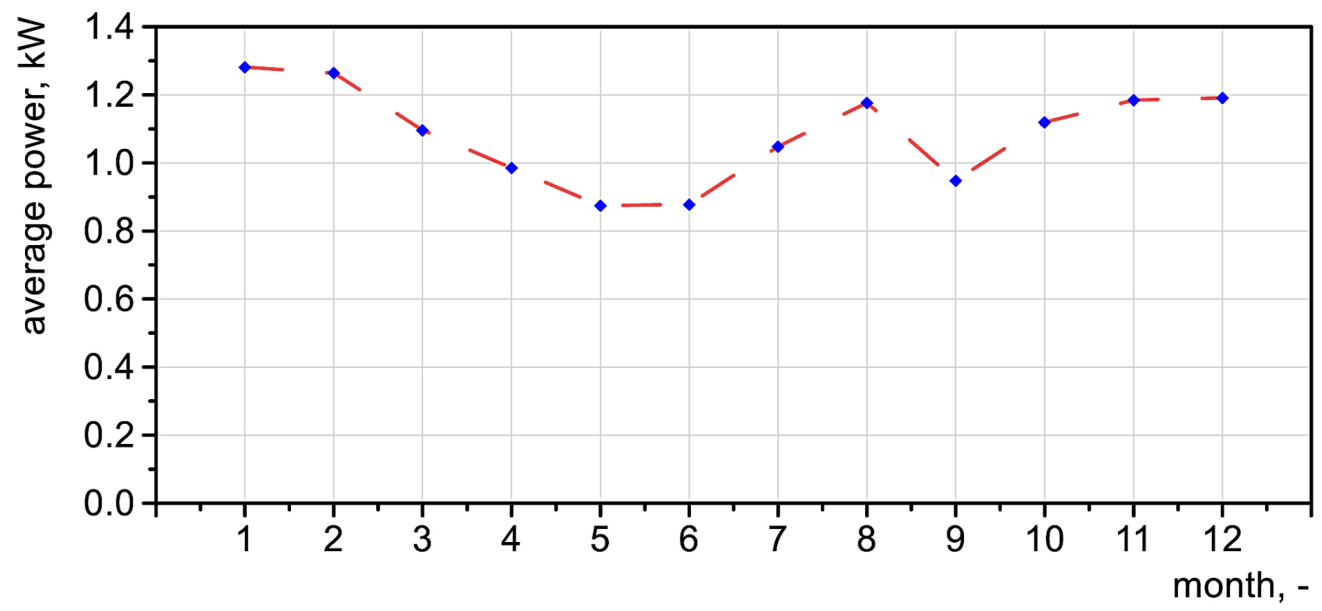

Fig. 7. Electric power generated on-board per hour of operation 
air conditioning systems whose ventilation fans are main electricity-consuming devices.

Figure 7 shows the average electrical power consumed by on-board receivers over months. The lowest value, i.e. $0.87 \mathrm{~kW}$ was recorded in May, whereas the highest one, $1.28 \mathrm{~kW}$, in January. Fans are a significant electrical load, and their instantaneous power is proportional to the drop/ rise in ambient temperature. The bus interior as soon as the door opens needs to be quickly heated up in the winter or cooled in the summer.

Figure 8 shows the amount of braking electricity generated on-board in varied operating times. The results are correlated to the time when this state occurs, i.e. the period when electricity generated by the set of alternators results from recuperated kinetic energy in a driving vehicle. The amount of electricity consumed is proportional to operating time given in hours.

On average, the bus generates about $16.8 \%$ of electricity from stored kinetic and potential energies. In all of the operating periods, the amount of engine braking electricity to be generated is correlated linearly with the total electricity demand (Figure 9).

Figure 10 shows the shares of engine braking energy generated on board. The least share of recuperated electricity in the general electric balance is recorded in January and August, i.e. 15.6\% and $14.3 \%$, respectively, which means that over these periods the remaining operating states have the largest share. This figure also summarizes the share of engine braking time correlated with the entire operating time, which is on average $17.1 \%$. The share of engine braking time is marked along the line in the figure. In all of the months, the correlation between the engine braking time and the total operating time was proportional to the correlation between engine braking electricity and the total energy generated during operation. The most significant differences between the amount of energy recovered during braking and the engine braking time occurs in August. The bus generated then $14.3 \%$ of engine braking electricity, however, the share of this state reached $15.8 \%$.

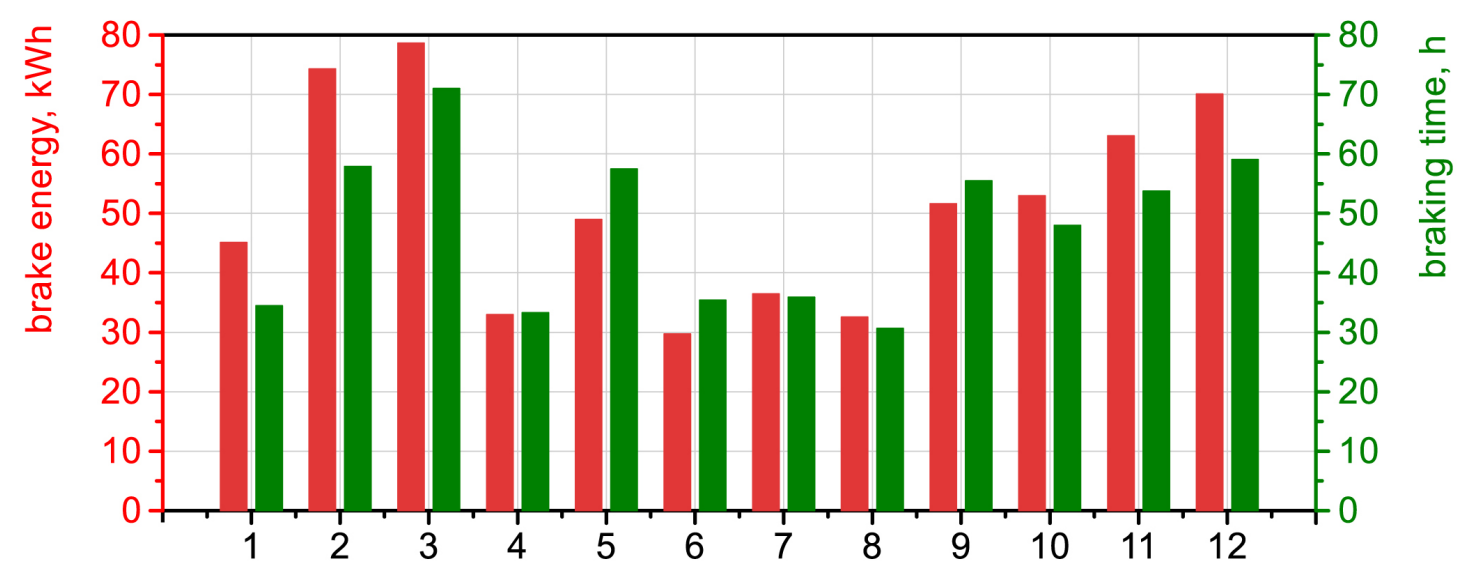

Fig. 8. Engine braking electricity generated and consumed on-board and the total time of this states over months

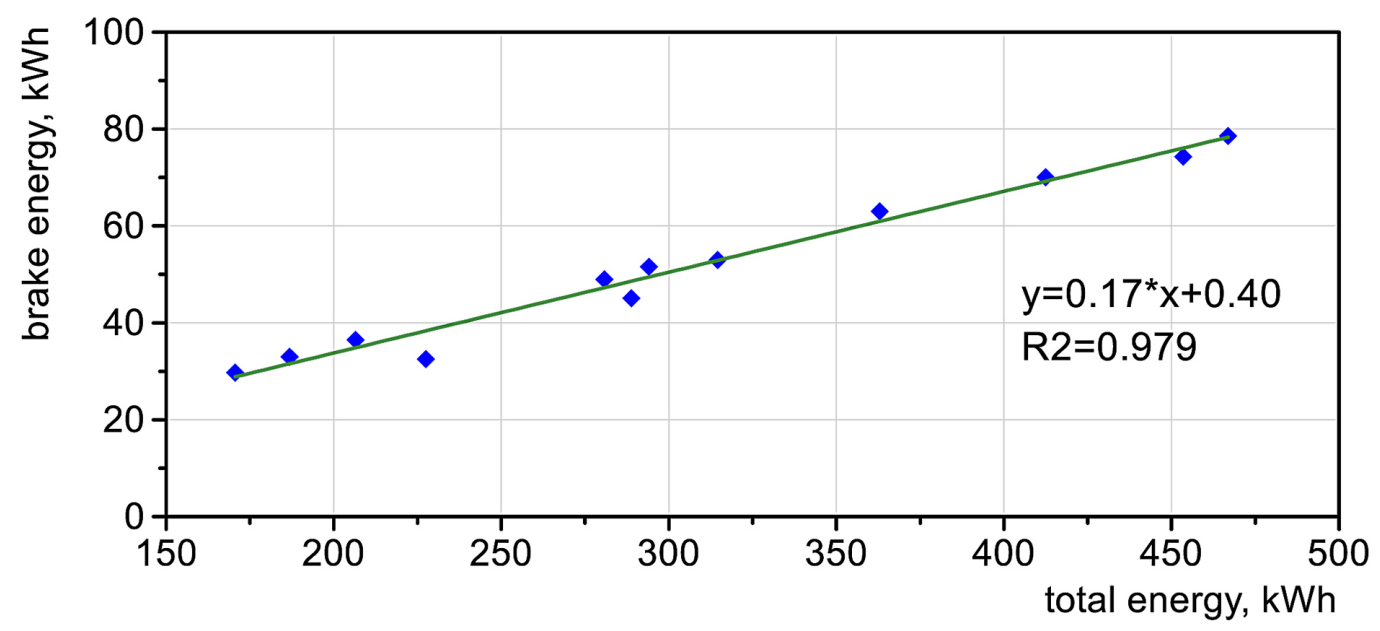

Fig. 9. Recuperated engine braking electricity vs. the total electricity demand 
In August, while engine braking, there was not a proportional amount of electricity in relation to the time of engine braking state when the bus generated electricity. These discrepancies can result from a small traffic during the summer season.

Frequent engine braking states are inherent to acceleration states so higher fuel consumption. Figure 11 shows the average fuel consumption per hour during vehicle's operation over different months.

The shares in each month are similar and differ by less than $1 \%$. This means that weather conditions and traffic do not significantly affect electricity generation in various operating states. However, electricity recovered from potential and kinetic energies over the next months was 80,51 and $74 \mathrm{kWh}$.

\section{CONCLUSIONS}

The engine braking state is inherent to city traffic bus operation. On average, it occurs over the year as $17 \%$ in relation to the entire operating time. The analysis carried out showed that the relationship between the total electricity consumption and the energy generated during the braking process is proportional and was described by a linear function. This is also apparent from the braking time share and braking energy share. The amount of energy generated during braking depends on the braking time. This is also due to the fact, that the average electrical output is similar throughout the year with an average of 1.1 $\mathrm{kW}$. As a result, a linear relationship can be expected between the above-mentioned indicators, i.e. braking time share and braking energy share.

In this state, a portion of stored potential and kinetic energies can be converted into electricity by a set of alternators to be used if increased onboard electricity consumption. Over the year, the bus consumes and generates approximately 3.7 MW of electricity out of which about $0.6 \mathrm{MW}$ in braking. The share of recovered energy can be increased by additional loading systems that can put a maximum load to alternators and transfer an excessive amount of energy to electricity-storage buffer systems, i.e. batteries. The maximum

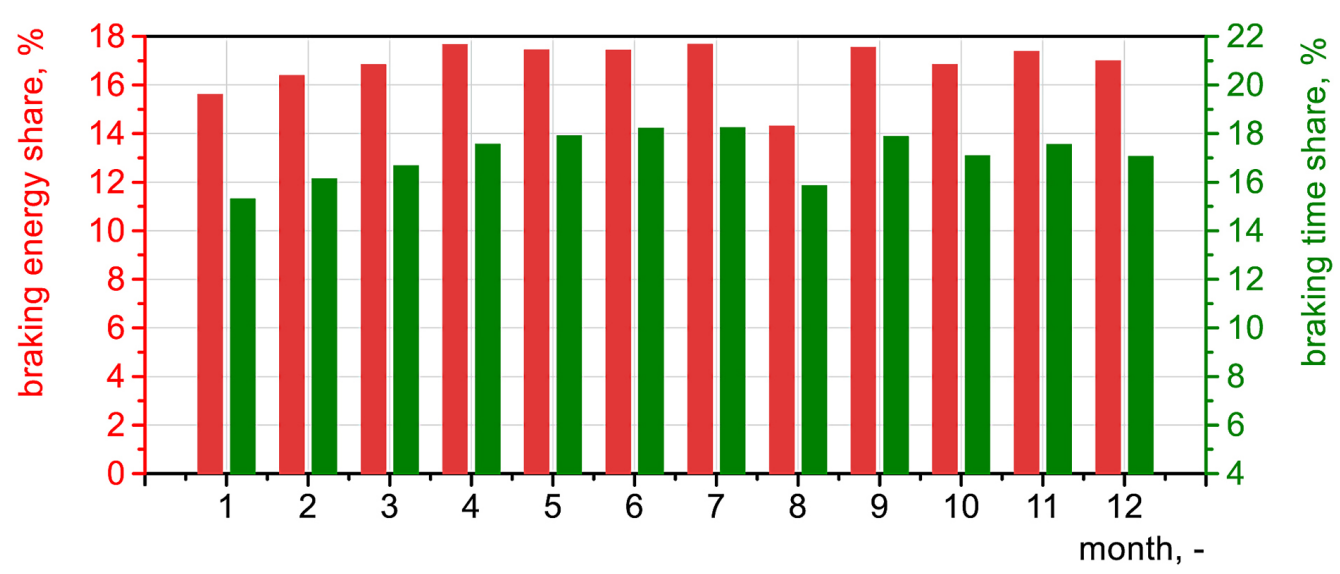

Fig. 10. Share of recovered engine braking electricity and the time share of this state in each month of operation

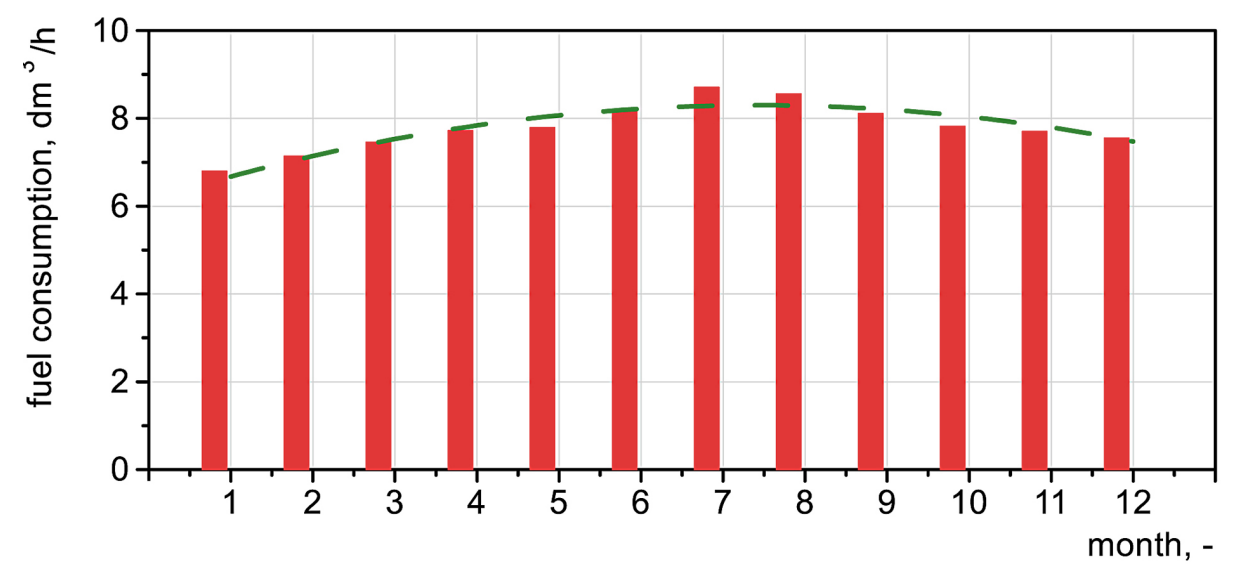

Fig. 11. Average fuel consumption in each month of operation 
amount of recoverable energy depends mainly on a changing operating point of a set of alternators (load as a function of rotational speed). In conclusion, it should be stated that the kinetic and potential energy stored on the bus can provide an additional source to drive the alternator.

\section{Acknowledgement}

The research was financed in the framework of the project Lublin University of TechnologyRegional Excellence Initiative, funded by the Polish Ministry of Science and Higher Education (contract no. 030/RID/2018/19).

\section{REFERENCES}

1. Zhang W.G.., Han Y.D., Li F.L. Braking Energy Regeneration System of Buses Based on Compressed Air Energy Storage. In: Huang DS., Heutte L., Loog M. (eds) Advanced Intelligent Computing Theories and Applications. With Aspects of Theoretical and Methodological Issues. ICIC 2007. Lecture Notes in Computer Science, Springer, Berlin, Heidelberg. 4681.

2. Granryd E., Ekroth I., Lundqouist P., Melinder A., Palm B., Rohlin P. Refrigerating Engineering. Department of Energy Technology, Division of Applied Thermodynamics and Refrigeration. Royal Institute of Technology. Stockholm; 2002.

3. Gao Y., Chen L., Ehsani M. Investigation of the effectiveness of regenerative braking for $\mathrm{EV}$ and HEV. SAE Technical Paper 1999-01-2910.

4. Sovran G. and Blaser D. Quantifying the potential impacts of regenerative braking on a vehicle's tractive-fuel consumption for the U.S. European, and Japanese driving schedules, SAE Technical Paper 2006-01-0664.
5. J. Zhang J., Lv C., Gou J., Kong D. Cooperative control of regenerative braking and hydraulic braking of an electrified passenger car. Proc Inst Mech Eng, Part D: J Automob Eng., 2012;226(10):1289-1302.

6. Grabowski Ł., Pietrykowski K., Gęca M., Barański G. The Electric Power Generation Efficiency in City Bus. SAE Technical Paper 2014-01-289.

7. Merkisz J., Bajerlein M., DaszkiewiczP. The Influence of the Application of Photovoltaic Cells in City Buses to Reduce Fuel Consumption - (CO2) and Exhaust Emissions (HC, PM, and NOx). 2012 International Conference on Power and Energy Systems, Lecture Notes in Information Technology. 2012;13:106-113.

8. Donno M., Ferrari A., Scarpelli A., Perlo P., Bocca A. Mechatronic system for energy efficiency in bus transport. Design, Automation \& Test in Europe Conference \& Exhibition (DATE). 2012;342-343.

9. Thomas V.M., Meier A.K., Gunda S.G., Wenze T.P. Cars are buildings: Building-like energy use in automobiles. Transportation Research. 2011;D(16):341-345.

10. Gęca M., Wendeker M., Grabowski Ł. A City Bus Electrification Supported by the Photovoltaic Power Modules. SAE Technical Paper 2014-01-2898.

11. Miller J.M., Goel D., Kaminski D., Schoner H.P., Jahns T.M. Making the case for a next generation automotive electrical system, in Proc. IEEE-SAE International Conference on Transportation Electronics (Convergence); 1998.

12. Miller J.M. Multiple voltage electrical power distribution system for automotive applications, in Proc. 31st Intersociety Energy Conversion Engineering Conference (IECEC), Washington 1996.

13. Reduction and Testing of Greenhouse Gas Emissions from Heavy Duty Vehicles - LOT 2 Development and testing of a certification procedure for $\mathrm{CO} 2$ emissions and fuel consumption of HDV Contract $\mathrm{N}^{\circ}$ 070307/2009/548300/SER/C3. Final Report 9. 2012. 